\title{
Message from previous Editor-in-Chief - Many thanks and expectations
}

\section{Toshihiko Ishimitsu ${ }^{1}$}

Published online: 5 January 2021

(c) The Japanese Society of Hypertension 2021

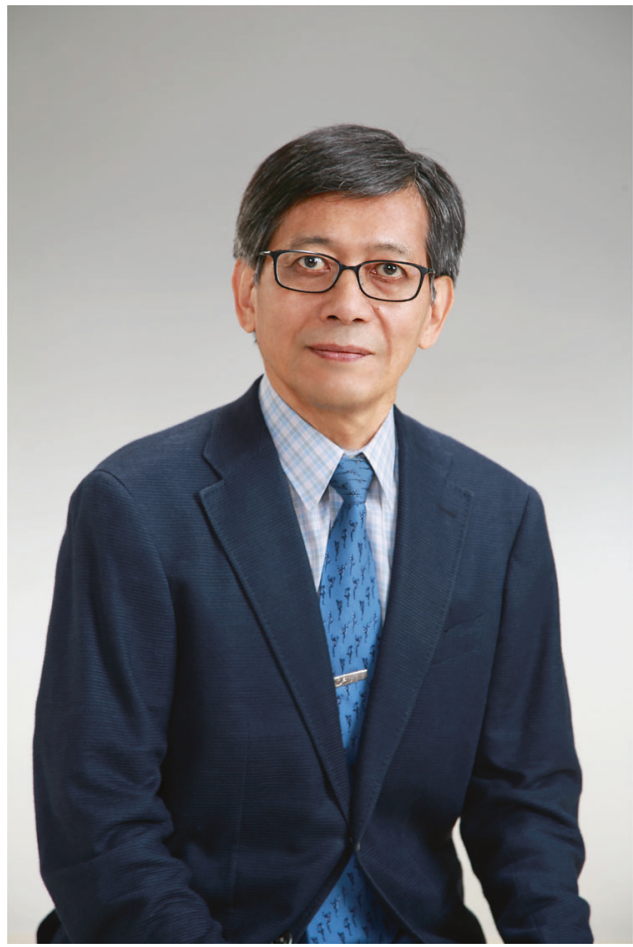

I had handed over the task of Editor-in-Chief of this journal, Hypertension Research, in 2014. At that time, the submissions of manuscripts were around 500 per year, while as many as 681 manuscripts were submitted in 2019 and the number is expected to exceed 700 in 2020 . We are greatly thankful for this increasing interest of researchers contributing to the valuable manuscripts. With regard to the handling of this increasing number of submitted manuscripts, I am much grateful to the generous efforts of associate editors, reviewers, staffs of the editorial office and the publisher, Springer Nature. During the process of publishing research articles, we have been forced to cope with some issues such as securing the quality of information and appropriate disclosure of the conflicts of interest.

At this time, we are facing with the pandemic spread of COVID-19 infection, which exerts a wide range of influences including the publication of medical research articles. Disability caused by COVID-19 certainly hampers the process of manuscript handling on one hand, however, it also provides new research questions concerning hypertension. Is hypertension a risk of SARS-CoV-2 infection and the disease severity? Does antihypertensive therapy using ACE inhibitors and angiotensin II receptor blockers increase the risk of infection or rather have protective effects against the progression of tissue and organ injuries? Actually, more than 50 manuscripts concerning COVID-19 have been submitted to Hypertension Research from February to October, 2020 including comprehensive and excellent review articles.

From January 2021, Editor-in-Chief of the journal is taken over by Professor Kazuomi Kario of Jichi Medical University. As he is an outstanding and leading scientist especially in the area of hypertension, I hope and believe that he will make the most of every opportunity hereafter and raise the quality of this journal, Hypertension Research. I also wish and would like to encourage researchers on hypertension and related matters worldwide to contribute to submitting and helping to evaluate a number of interesting manuscripts attractive to the international readers.
Toshihiko Ishimitsu

isimitu@dokkyomed.ac.jp

1 Department of Nephrology and Hypertension, Dokkyo Medical University, Mibu, Japan 